\title{
Unusually Large Submandibular Sialoliths: Report of Two Cases
}

\author{
Meryem Toraman Alkurta \\ Ilkay Peker ${ }^{\text {b }}$
}

\section{ABSTRACT}

Sialoliths are the most common diseases of the salivary glands. They may occur in any of the salivary gland ducts but are most common in Wharton's duct and the submandibular gland. This report presents clinical and radiographical signs of two unusually large sialoliths. There were painless swellings on the floor of the mouth in both cases. Radiographical examination revealed large irregular radioopaque mass superimposed right canine and premolar areas. After the lesions were removed, histopathological examination was performed and lesions were diagnosed as sialoliths. (Eur J Dent 2009;3:135-139)

Key words: Sialolith; Submandibular gland; Wharton's duct.

\section{INTRODUCTION}

Sialoliths are the most common diseases of the salivary glands. ${ }^{1}$ They are stones within the major and minor salivary glands or in the ducts of these glands. ${ }^{2}$ More than $80 \%$ occur in the submandibular gland or its duct, ${ }^{3}$ probably because of its more viscous saliva, longer duct, and higher mineral content in the saliva, $4-10 \%$ in

\footnotetext{
a Assistant Professor, Gazi University, Faculty of Dentistry, Department of Oral Diagnosis and Radiology, Ankara,Turkey.

b Research Assistant, Gazi University, Faculty of Dentistry, Department of Oral Diagnosis and Radiology, Ankara,Turkey.

- Corresponding author: Dr. Meryem Toraman Alkurt Gazi University, Faculty of Dentistry, Department of Oral Diagnosis and Radiology 8. Cadde 82. Sokak 06490 Emek / Ankara, Turkey. Phone: +903122034152 Fax : +903122239226 E-mail: mtalkurtagmail.com
}

the parotid gland and $1-7 \%$ in the sublingual gland or minor salivary glands. ${ }^{2}$ The etiological factors of the sialoliths are unknown, but inflammation is the widely accepted causative condition. ${ }^{4}$

The aim of this report was to present clinical and radiographical features of two cases of large submandibular sialoliths.

\section{CASE REPORTS}

\section{Case 1}

A 45 year old man presented to Gazi University, Faculty of Dentistry, Department of Oral Diagnosis and Radiology for a firm mass with whitish color in the anterior part of the right side of the floor of the mouth. Medical history of the patient was not remarkable. He reported that the lesion was painless and there was no history of swelling. He was aware of the lesion for one week. 
Extraoral examination revealed no swelling and no palpable mass. In intraoral examination, bimanual palpation revealed a hard elongated mass with whitish color along the right Wharton's duct and a grayish-white mass was observed at the orifice of right submandibular gland. Panoramic and occlusal radiographs were obtained for radiographical examination. Panoramic radiograph revealed a large irregular radioopaque mass superimposed on right canine and premolar areas (Figure 1). The large radioopaque sialolith was observed in right Wharton's duct on mandibular occlusal radiograph (Figure 2).

The patient was reexamined by the clinician after radiographical examination. The lesion moved and surprisingly felt with some pus flow into the floor of the mouth while the clinician was checking the salivary flux by slight pressure to the submandibular region. The lesion size was $2.8 \times 0.8$ x $0.4 \mathrm{~cm}$ (Figure 3). Histopathological validation was performed and during decalcification process the lesion dispersed as concentric lamellas. On the basis of clinical, radiographical and histopathological findings, the lesion diagnosed as submandibular sialolith.

\section{Case 2}

A 65 year old man presented to Gazi University, Faculty of Dentistry, Department of Oral Diagnosis and Radiology to replace his removable prosthesis. Medical history showed that the patient had Parkinson disease, hypertension and coronary heart disease and he took regularly antihypertensive, antiparkinsonism and coronary heart disease drugs for approximately ten years. In dental history, the patient complained of dry mouth and he reported a painless swelling during mealtimes in the floor of the mouth for approximately 3 years.

Extraoral examination revealed no swelling and no palpable mass. During intraoral examination,

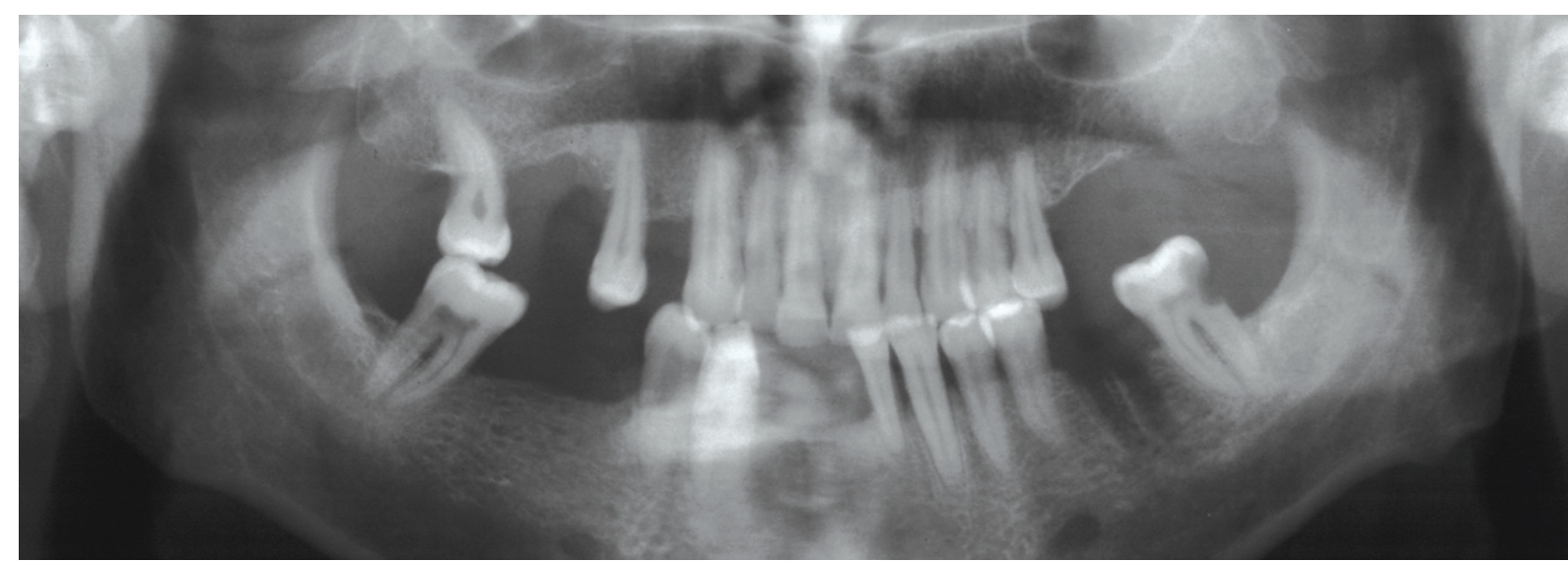

Figure 1. Panoramic radiograph of case 1.

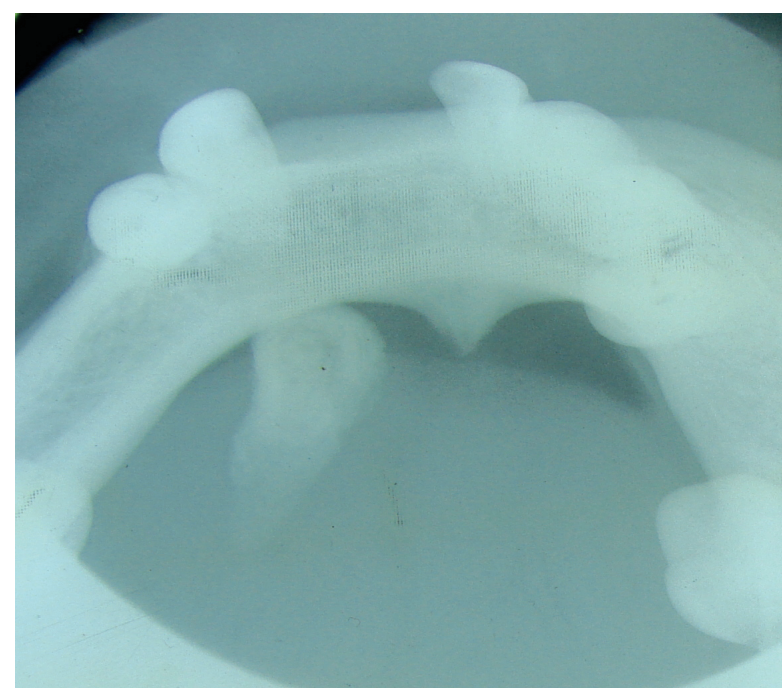

Figure 2. Occlusal radiograph of case 1.

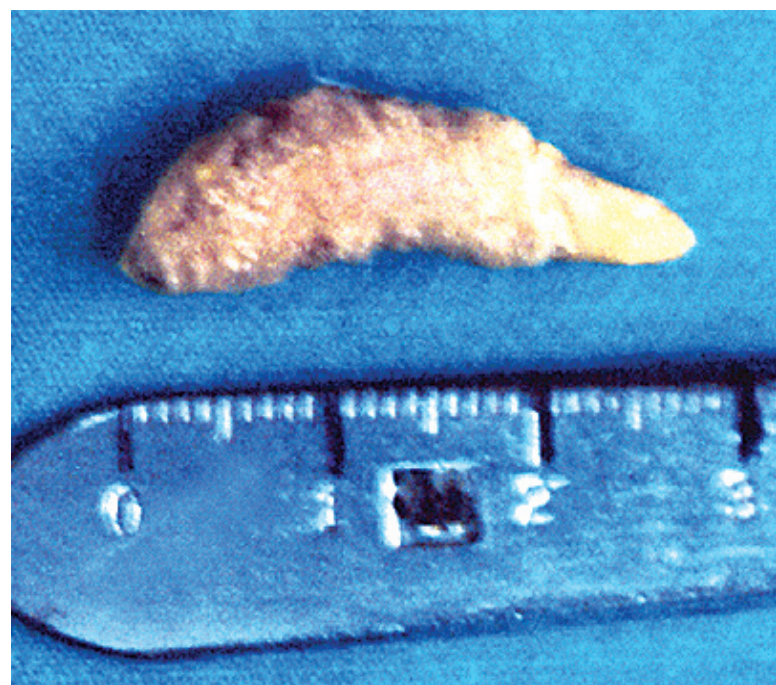

Figure 3 . Sialolith of case 1. 
bimanual palpation revealed a hard and slightly sensitive swelling with whitish color along the right Wharton's duct in the right anterior floor of the mouth. Salivary flux was normal and nonenlarged duct's orifice was observed in the right submandibular gland.

Panoramic and occlusal radiographs were obtained for radiographical examination. Panoramic radiograph revealed a large irregular radioopaque mass superimposed on right canine and premolar areas (Figure 4). A large radioopaque sialolith was observed in right Wharton's duct on mandibular occlusal radiograph (Figure 5). The lesion was excised surgically, the lesion size was $3.1 \times 1.0 \times 0.7$ $\mathrm{cm}$ (Figure 6). Histopathological validation was performed and during decalcification process the lesion dispersed as concentric lamellas. On the basis of clinical, radiographical and histopathological findings, the lesion diagnosed as submandibular sialolith.

\section{DISCUSSION}

Salivary calculi are usually small and measure from $1 \mathrm{~mm}$ to less than $1 \mathrm{~cm}$. They rarely measure more than $1.5 \mathrm{~cm}^{5,6}$ Mean size is reported as 6 to $9 \mathrm{~mm} .7,8$ Giant sialoliths are rare and defined as the size of $3.5 \mathrm{~cm}$ or larger. ${ }^{5}$ Large and giant calculi may perforate the floor of the mouth by ulcerating the duct or may result in a skin fistula by causing a suppurative infection. ${ }^{9}$ It was reported that the most common symptoms of sialoliths are recurrent pain and swelling of the associated gland during meals, because the stone usually does not block the flow of saliva completely. 6,10 However, large sialoliths have been frequently reported in the body of salivary glands, they have rarely been described in the salivary ducts, particularly without any complaints from the patients. ${ }^{1,11}$ In this report, clinical and radiological features of two large sialoliths which were in the size of 2.8 and 3.1 centimeters were presented. They were located into Wharton's ducts and the

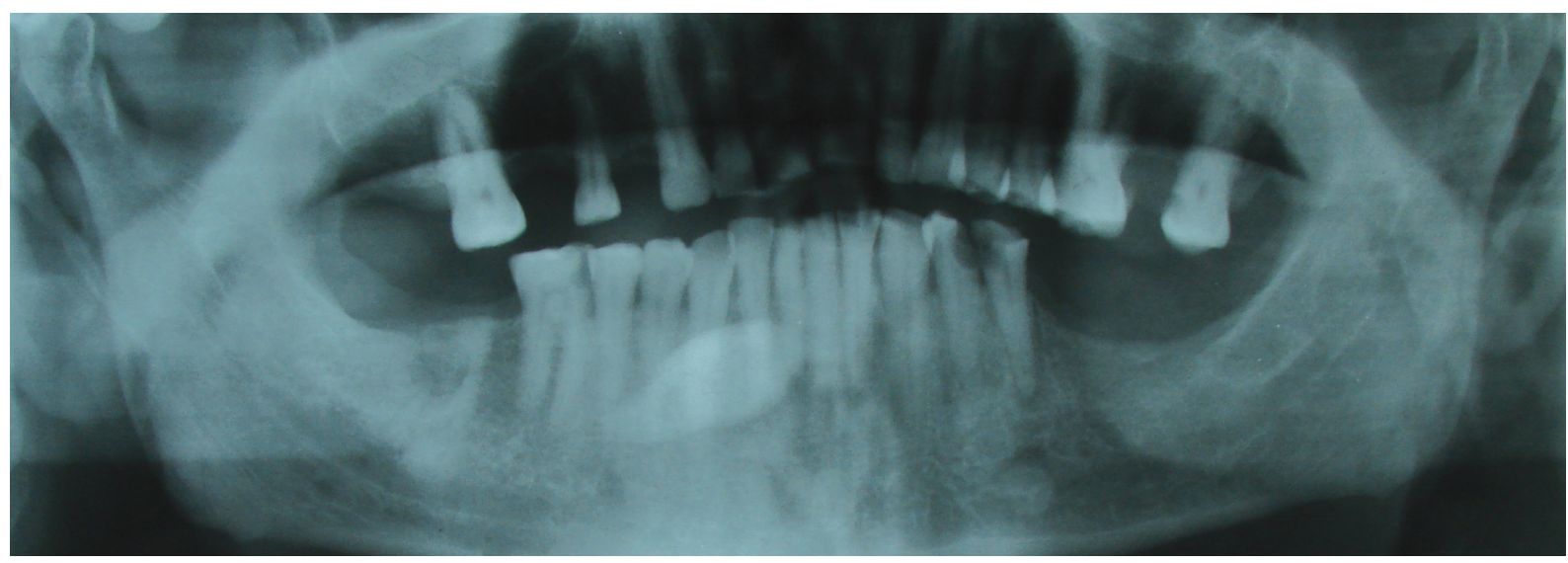

Figure 4. Panoramic radiograph of case 2.

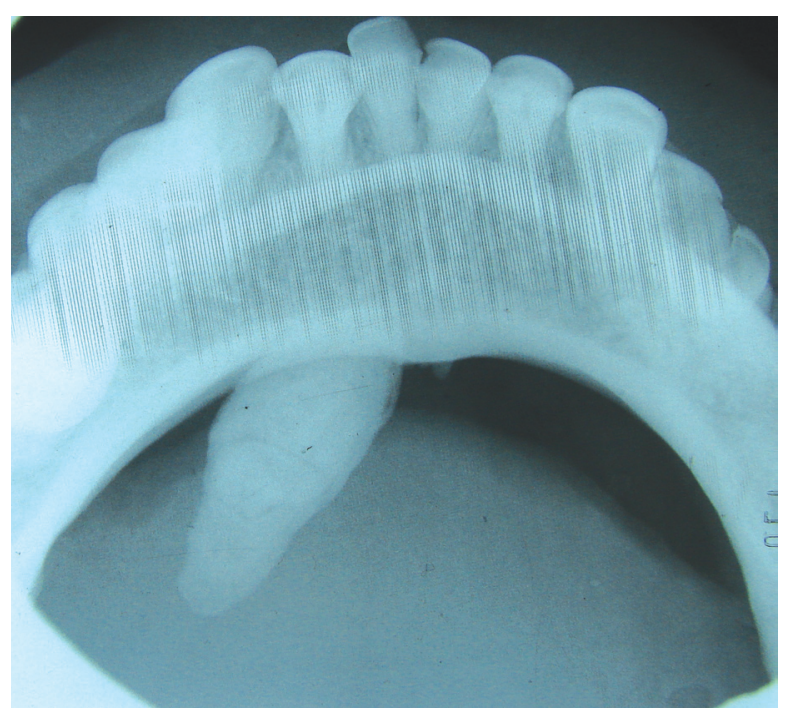

Figure 5. Occlusal radiograph of case 2 .

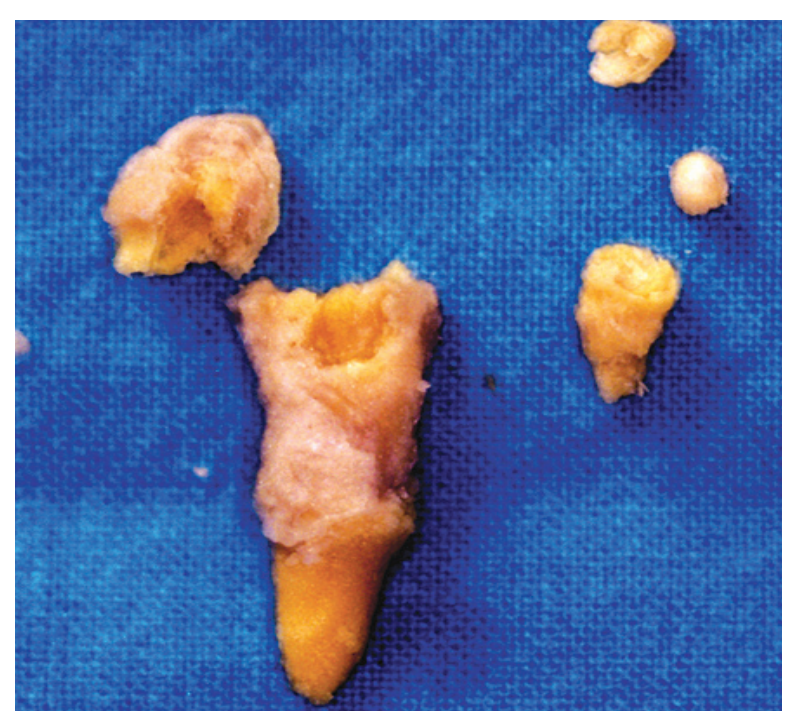

Figure 6. Sialolith of case 2.

April 2009 - Vol.3 
patients complained painless swelling. In case 1 , the sialolith had erupted from the orifice of submandibular gland and the lesion moved and felt with some pus flow into floor of the mouth during extraoral palpation of the submandibular region. In case 2 , the patient complained of dry mouth. This condition was thought to be related with the regular usage of many drugs lantihypertensive, antiparkinsonism and coronary heart disease drugs) and the patient's age.

Some unusual large salivary calculi may be seen without a long history, because of the lesions were generally asymptomatic. ${ }^{6}$ It is believed that a calculus may enlarge at the rate of approximately 1 to $1.5 \mathrm{~mm}$ per year. ${ }^{12}$ With this context, it is possible to estimate that our cases began to develop many years ago.

Careful history and examination are important in the diagnosis of sialoliths. Pain and swelling of the concerned gland at mealtimes and in response to other salivary stimuli are especially important. Bimanual palpation of the floor of the mouth, in a posterior to anterior direction, reveals a palpable stone in a large number of cases of submandibular calculi formation. Bimanual palpation of the gland itself can be useful, as a uniformly firm and hard gland suggests a hypofunctional or non-functional gland. ${ }^{3,13}$ When there was no history of pain or swelling at mealtimes in case 1 , the patient complained a painless swelling in the floor of the mouth at mealtimes in case 2. Bimanual palpation was performed in intraoral and extraoral examinations. No palpable mass was observed in extraoral examination, while the lesion moved and felt with some pus flow into floor of the mouth during slight pressure for case 1 and a sensitive swelling was observed for case 2.

Imaging studies are very useful for diagnosing sialolith. The best view for visualizing radiopaque stones is a standard mandibular occlusal radiograph. ${ }^{3}$ Other traditional diagnostic methods include sialography, ultrasound, computed tomography and scintigraphy for sialoliths. ${ }^{14,15}$ Currently, magnetic resonance sialography obtained in two or three dimensional images is suggested for diagnosis of sialoliths, but these methods are not suitable to see the inner duct system of the salivary glands. ${ }^{16}$ Sialoendoscopic system was developed in the 1990's as an endoscopic technique, and provides to examine the ductal system completely due to the scopes are so small. ${ }^{17,18}$ Sialoendoscopy can be used for both diagnostic and treatment purposes. Yu et $\mathrm{al}^{19}$ reported that sialoendoscopy was superior to plain film or even to magnetic resonance imaging for especially the small and more distal located stones. In this report, as the lesions were observed clearly in occlusal radiographs, no further investigations were performed for diagnosis.

Different treatment options may be selected according to the size and location of the sialolith. ${ }^{3}$ Small stones often may be "milked out" through the ductal orifice using bimanual palpation. If the stone is too large or located in the proximal duct, piezoelectric extracorporal shock wave lithotripsy or surgical removal of the stone or gland may be required. ${ }^{7}$ Sialoendoscopy is a new way and minimally invasive technique for treating obstructions of the ductal system and can be used with operation in large salivary stones. ${ }^{19}$ Recurrent or continuous obstruction of the salivary duct may lead to acute or chronic sialadenitis or even to the perforation of the oral mucosa. ${ }^{6}$ In case 1, although the sialolith was very large $(2.8 \mathrm{~cm})$, it was removed surprisingly during bimanual palpation and the other was removed by surgical excision.

\section{CONCLUSIONS}

The clinicians should evaluate carefully the painful or painless swellings in submandibular area due to sialolith is the most common disease in submandibular gland and Wharton's duct. Large submandibular sialoliths should be treated by appropriate approach to prevent possible severe complications.

\section{ACKNOWLEDGEMENT}

The study was presented in $7^{\text {th }}$ International Congress of Aegean Region Chamber of Dentists, April 2007, Fethiye.

\section{REFERENCES}

1. Leung AK, Choi MC, Wagner GA. Multiple sialoliths and a sialolith of unusual size in the submandibular duct. Oral Surg Oral Med Oral Pathol Oral Radiol Endod 1999;87:331333 
2. Goaz PW, White SC. Oral Radiology, principles and interpretation. In: Goaz PW, White SC. Soft tissue calcifications. Mosby; St. Louis; 1994:626.

3. Siddiqui SJ. Sialolithiasis: an unusually large submandibular salivary stone. Br Dent J 2002;193:89-91.

4. Rice Dh. Salivary gland disorders: neoplastic and nonneoplastic. Med Clin North Am 1999;83:197-218.

5. Ledesma-Montes C, Garces-Ortiz M, Salcido-Garcia JF, Hernandez-Flores F, Hernandez-Guerrero JC. Giant sialolith: Case report and review of the literature. $J$ Oral Maxillofac Surg 2007;65:128-130.

6. Sutay S, Erdag TK, Ikiz AO, Guneri EA. Large submandibular gland calculus with perforation of the floor of the mouth. Otolaryngol Head Neck Surg 2003;128:587-588.

7. McGurk M, Escudier MP, Brown JE. Modern management of salivary calculi. Br J Surg 2005;92:107-112.

8. Zenk J, Constantinidis J, Al-Kadah B, Iro H. Transoral removal of submandibular stones. Arch Otolaryngol Head Neck Surg 2001;127:432-436.

9. Karengera D, Yousefpour A, Reychler H. Unusual elimination of a salivary calculus. Int J Oral Maxillofac Surg 1998;27:224-225

10. White SC, Pharoah MJ: Oral Radiology, principles and interpretation. In: Carter L. Soft tissue calcification and ossification. Mosby; St. Louis: 2004:603-605.

11. Graziani F, Vano M, Cei S, Mario G. Unusual asymptomatic giant sialolith of the submandibular gland: A clinical report. J Craniofac Surg 2006;17:549-552.

12. Norman JED: The natural history of lithogenesis and sialolithiasis, acute sialosepsis and sialodenitits. In: Norman JED, McGurk M, eds. Color atlas and text of the salivary glands. Diseases, disorders and surgery. London; Mosby-Wolfe; 1995:611-613.

13. Williams MF: Sialolithiasis. Otolaryngol Clin North Am $1999 ; 32: 819-834$

14. Lomas DJ, Carroll NR, Johnson G, Antoun NM, Freer CE. MR sialography: work in progress. Radiology 1996;200:129133.

15. Fischbach R, Kugel H, Ernst S, Schröder U, Brochhagen $H G$, Jungehülsing $M$, Heindel W. MR sialography: initial experience using a T2 weighted fast SE sequence. J Comput Assist Tomogr 1997;21:826-830.

16. Becker M, Marchal F, Becker CD, Dulguerov $P$, Georgakopoulos G, Lehmann W, Terrier F. Sialolithiasis and salivary duct stenosis: diagnostic accuracy of MR sialography with a three dimensional extended phase conjugate- symmetry rapid spin-echo sequence. Radiology 2000;217:347-358.
17. Konigsberger R, Feyh J, Goetz A, Kastenbauer E. Endoscopically controlled electrohydraulic intracorporeal shock wave lithotripsy (EISL) of salivary stones. JOtolaryngol 1993;22:12-13.

18. Arzoz E, Santiago A, Esnal F, Palomero R. Endoscopic intracorporeal lithotripsy for sialolithiasis. J Oral Maxillofac Surg 1996;54:847-852.

19. Yu CQ, Yang C, Zheng LY, Wu DM, Zhang J, Yun B. Selective management of obstructive submandibular sialadenitis. $\mathrm{Br}$ J Oral Maxillofac Surg 2008;46:46-49. 